\title{
LONG DISTANCE RT-PCRs OF HUMAN CORONAVIRUS 229E RNA
}

\author{
Volker Thiel, Jens Herold, and Stuart G. Siddell \\ Institute of Virology and Immunology \\ University of Wuerzburg \\ Versbacherstr. 7 \\ 97078 Wuerzburg, Germany
}

\section{ABSTRACT}

The generation and cloning of cDNA fragments longer than $10 \mathrm{~kb}$ is often a difficult and time consuming task. In this study, we have analysed the conditions necessary to produce reverse transcripts longer than $10 \mathrm{~kb}$ that can be amplified by polymerase chain reaction. Thus, we isolated poly(A)-RNA from human coronavirus 229E infected MRC-5 cells and did reverse transcription using a sequence-specific primer. Subsequently, we amplified PCR products of varying length upstream of the primer position. Optimisation of the poly(A)-RNA preparation, the reverse transcription protocol and the polymerase chain reaction cycle conditions enabled us to successfully amplify regions of the human coronavirus 229E genome between 11.5 and $20.3 \mathrm{~kb}$ in length.

\section{INTRODUCTION}

Polymerase chain reaction (PCR) and related techniques have become an almost indispensible tool in biological research and medicine. Consequently, there is a constant effort to improve the sensitivity and specificity of the procedure and to extend the application of PCR and related techniques to an increasing range of problems. For example, PCR technology has been adapted to the amplification of long DNA templates and to DNA templates of a more complex nature, i.e. human genomic DNA and mitochondrial DNA (Barnes, 1994; Cheng et al., 1994a; Cheng et al., 1994b). PCR, combined with reverse transcription (RT), is also a suitable method for the production of DNA from RNA templates. However only a few reports describe RT-PCR protocols that enable the amplifcation of DNAs longer than about 7 kilobases (Kb) (Fakhfakh et al., 1996; Martinez et al., 1996; Tellier et al., 1996). Here we report our studies on the conditions necessary to produce RT-PCR products longer than $10 \mathrm{~kb}$ using HCV 229E RNA as a template for reverse 
transcription. We focused, especially, on the requirements of the RNA template, the reverse transcription and the amplification of the cDNA. To carry out these studies, we used the HCV 229E genomic RNA as template and HCV 229E specific oligonucleotides to prime the reverse transcription. Then we tried to amplify products of varying length upstream of the RT-primer position.

\section{METHODS}

\subsection{Preparation of Polyadenylated RNA}

MRC-5 cells were infected with $\mathrm{HCV} 229 \mathrm{E}$ at a m.o.i. of 10 , incubated at $33^{\circ} \mathrm{C}$ and polyadenylated RNA was prepared $18 \mathrm{~h}$ p.i. using two different methods. First, cytoplasmic RNA was prepared by phenol extraction and ethanol precipitation and poly(A)-RNA was selected by chromatography on poly(U)-Sepharose. The second method is based on preparation of poly(A)-RNA using oligo-(dT) ${ }_{25}$-dynabeads (Dynal, Germany).

\subsection{RT-PCR}

Polyadenylated RNA (200 ng) from HCV 229E infected MRC-5 cells and $30 \mathrm{ng}$ of oligonucleotide primer were used for reverse transcription in a volume of $20 \mu \mathrm{l}$ with 200 U Superscript II reverse transcriptase (Life Technologies). The reactions were carried out for $90 \mathrm{~min}$ at $42^{\circ} \mathrm{C}$, then heated for $2 \mathrm{~min}$ at $94^{\circ} \mathrm{C}$ and chilled on ice.

Aliquots $(0.5 \mu \mathrm{l})$ of the reverse transcription reaction were used for the PCR. Reactions were performed in a total volume of $50 \mu \mathrm{l}$ using the Elongase Enzyme Mix (Life Technologies) according to the manufacturer's instructions. Unless otherwise indicated, the PCR cycles were: $1 \mathrm{~min} 94^{\circ} \mathrm{C}$, followed by 30 cycles of $20 \mathrm{~s}$ denaturation at $94^{\circ} \mathrm{C}, 30$ $\mathrm{s}$ annealing at $50^{\circ} \mathrm{C}$ and elongation for $1 \mathrm{~min}$ per $\mathrm{kb}$ of expected product length at $68^{\circ} \mathrm{C}$. During the last 18 cycles the elongation time was increased by $30 \mathrm{~s}$ per cycle. The reaction was terminated by a 10 min elongation at $72^{\circ} \mathrm{C}$.

\section{RESULTS}

MRC-5 cells were infected with HCV 229E and the poly(A)-containing RNA was prepared using poly(U)-Sepharose or oligo-(dT) ${ }_{25}$ coupled to magnetic beads. The poly(A)-containing RNAs were separated by gel elecrophoresis and the viral mRNAs were visualised by hybridisation analysis (Figure 1). In both preparations, it is possible to identify the genomic RNA and the six subgenomic mRNAs that are characteristic of HCV $229 \mathrm{E}$ infection. The viral RNAs are more abundant in the material isolated by poly(U)Sepharose, however, the hybridisation analysis indicates that the material isolated with oligo $(\mathrm{dT})_{25}$ magnetic beads is less degraded.

In order to generate HCV 229E specific cDNAs we performed reverse transcriptions with HCV 229E specific oligonucleotides and the RNA templates shown in Figure 1. To amplify DNA products from the HCV 229E cDNAs, we inserted aliquots of the RT reaction into the PCR. Up to a distance of $4.8 \mathrm{~kb}$ from the RT priming site, we were able to obtain the expected PCR products regardless of the poly(A)-containing RNA preparation that we used as template for the RT reaction. However, when we tried to synthesise longer PCR products, we only succeeded with the poly(A)-RNA template prepared by the Dyna- 
Figure 1. Hybridisation analysis of HCV 229E specific RNAs. Poly(A)-RNA $(0.5 \mu \mathrm{g})$ prepared from HCV 229E-infected cells using poly(U)-Sepharose or oligo-(dT) ${ }_{25}$ magnetic beads was separated by electrophoresis. Viral RNAs were hybridised with a HCV $229 \mathrm{E}$ nucleocapsid gene-specific, 5'-endlabelled oligonucleotide.

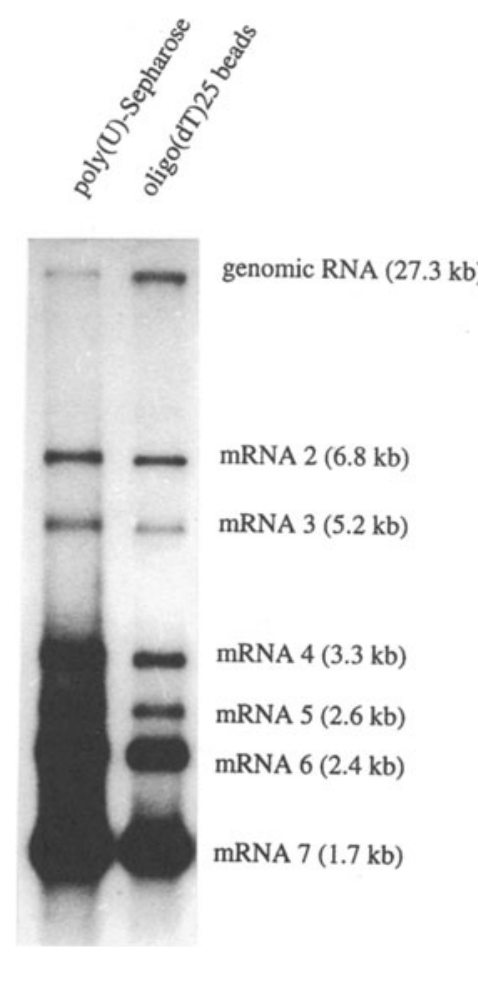

beads method. This result indicates that the quality of the RNA preparation is important when RT-PCR products longer than $4.8 \mathrm{~kb}$ are desired.

We then established an RT-PCR protocol that enabled us to generate a DNA product with a size of $12.6 \mathrm{~kb}$. As RNA template we used the poly(A)-containing RNA that was prepared from HCV $229 \mathrm{E}$ infected cells using oligo-(dT) ${ }_{25}$ magnetic beads. We primed the reverse transcription with the oligonucleotide 85 (Figure $2 \mathrm{a}$ ). Two microliter of this reverse transcription reaction then served as template for a subsequent PCR reaction with the primers 159 and 89. As is shown in Figure $2 \mathrm{~b}$ (lane 2), we obtained a PCR product with the expected size of $12.6 \mathrm{~kb}$.

Our next goal was to amplify cDNAs longer than $12.6 \mathrm{~kb}$. Therefore, we primed the reverse transcription with the oligonucleotide 32 (Figure 2a). First a PCR was done with $0.5 \mu \mathrm{l}$ of the RT reaction as template and the primers 27 and 11 . As shown in Figure $2 \mathrm{~b}$, it was possible to amplify a DNA fragment with the expected size of $11.5 \mathrm{~kb}$ (lane 1 ). Using the same protocol, we successfully amplified DNA fragments of $16.7 \mathrm{~kb}$ and $17.5 \mathrm{~kb}$ in length (Figure $2 \mathrm{~b}$, lanes 3 and 4 ). It was also possible to synthesise DNA products of 19.0 and $20.3 \mathrm{~kb}$, however the yields of these products were relatively poor. We therefore optimised the PCR conditions by varying the cycle profile. As is shown in Figure 2b, lanes 5 and 6 , a profile of 5 cycles with $5 \mathrm{~s}$ at $94^{\circ} \mathrm{C}, 20 \mathrm{~s}$ at $50^{\circ} \mathrm{C}, 23 \mathrm{~min}$ at $68^{\circ} \mathrm{C}$ and 25 cycles with $5 \mathrm{~s}$ at $94^{\circ} \mathrm{C}, 23 \mathrm{~min}$ at $68^{\circ} \mathrm{C}$ plus 30s per cycle increased the specificity of these PCRs and greatly enhanced the synthesis of the 19.0 and $20.3 \mathrm{~kb}$ RT-PCR products. 
A

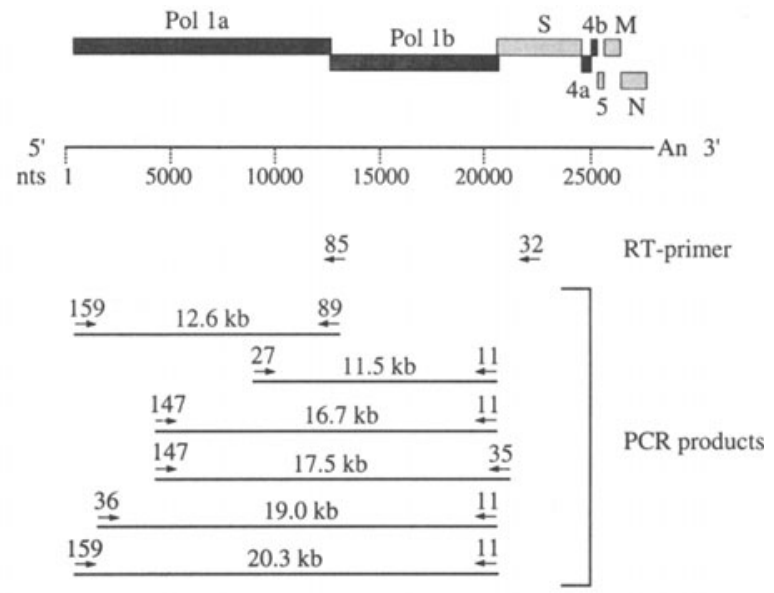

B

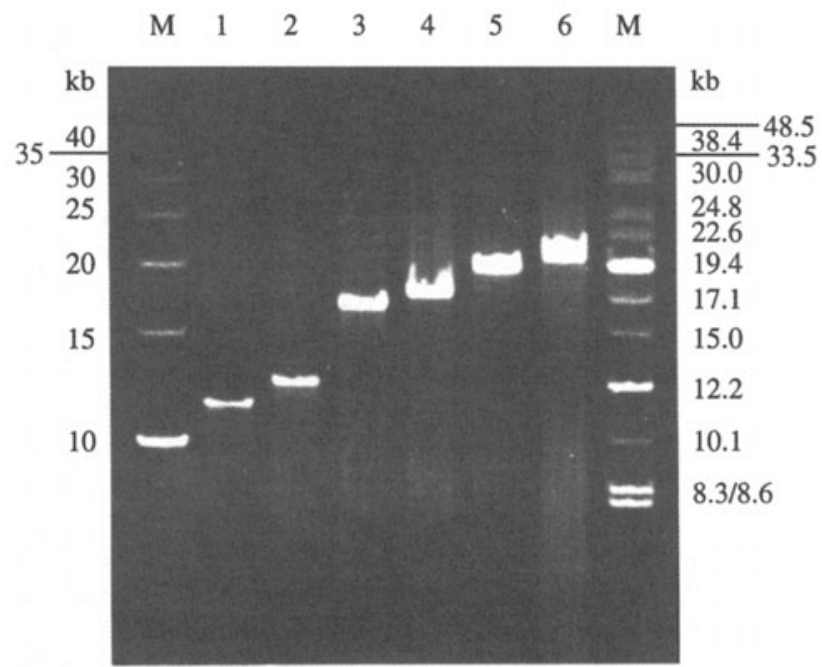

Figure 2. RT-PCRs of HCV 229E RNA. A) Schematic representation of HCV 229E specific oligonucleotides and RT-PCR products. The oligonucleotides are indicated as arrows according to their orientation and position relative to the HCV 229E genomic RNA. The expected sizes of the RT-PCR products are indicated. B) RT-PCR products of HCV 229E RNA. Five microliters of the PCR reactions were separated by PFGE along with a $5 \mathrm{~kb}$ DNA ladder and a high molecular weight marker. The sizes of the RT-PCR products and markers are indicated.

\section{DISCUSSION}

In this study, we have combined the concept of long PCR technology to reverse transcription PCR. We have demonstrated that there is no limitation concerning the ability of reverse transcriptase to synthesise cDNAs of up to $20 \mathrm{~kb}$. However, to achieve this goal, a number of critical parameters have to be kept in mind. First the integrity of the RNA tem- 
plate is an important prerequisite to perform long RT-PCRs. Second the conditions of the reverse transcription reaction strongly influence the outcome of the subsequent PCR. Thus, "non-stringent" priming during the RT reaction can be responsible for background amplification but this problem can be overcome by minimising the RT-primer concentration in the RT reaction. Finally, as is the case for all PCRs, the cycle conditions have to be optimised according to the amount of template, the PCR primers and the cycle profile.

The system that we have described has been applied to the amplification of viral RNA sequences. There are a number of RNA viruses with genome lengths above $10 \mathrm{~kb}$, and for many of them it would be very desirable to develop a simple and reproducible system for the generation of genomic cDNA clones or RT-PCR DNA that represents a quasispecies population. An approach using long RT-PCRs to generate full length cDNAs in vitro could solve many of the problems encountered with conventional cloning techniques. The ability to obtain RT-PCR products up to $20 \mathrm{~kb}$, in microgram amounts, greatly extends the number of RNA viruses that become amenable to this approach.

\section{REFERENCES}

Barnes, W.M., 1994, PCR amplification of up to 35-kb DNA with high fidelity and high yield from 1 bacteriophage templates, Proc. Natl. Acad. Sci. USA 91: 2216-2220.

Cheng, S., C. Fockler, W.M. Barnes, and R. Higuchi., 1994a, Effective amplification of long targets from cloned inserts and human genomic DNA, Proc. Natl. Acad. Sci. USA 91: 5695-5699.

Cheng, S., R. Higuchi, and M. Stoneking, 1994b, Complete mitochondrial genome amplification. Nature Genet. 7: $350-351$.

Chumakov, K.M., 1996, PCR Engeneering of Viral Quasispecies: a New Method To Preserve and Manipulate Genetic Diversity of RNA Virus Populations, J. Virol. 70: 7331-7334.

Fakhfakh, H., F. Vilaine, M. Makni, and C. Robaglia., 1996, Cell-free cloning and biolistic inoculation of an infectious cDNA of potato virus Y, J. Gen. Virol. 77: 519-523.

Martinez, J.M., H.H. Breidenbach, and R. Cawthon, 1996, Long RT-PCR of the Entire 8.5-kb NF1 Open Reading Frame and Mutation Detection on Agarose Gels, Genome Res. 6: 58-66.

Tellier, R., J. Bukh, S.U. Emerson, and R.H. Purcell., 1996, Amplification of the full-length hepatitis A virus genome by long reverse transcription-PCR and transcription of infectious RNA directly from the amplicon, Proc. Natl. Acad. Sci. USA 93: 4370-4373. 